\title{
An analysis of tubal ectopic pregnancy in a rural tertiary care hospital in India: a retrospective study
}

\section{Chandana Galidevara ${ }^{1}$, Swaramya $\mathrm{C}_{.}{ }^{2 *}$}

\begin{abstract}
${ }^{1}$ Department of Obstetrics and Gynaecology, Mahatma Gandhi Medical College and Research Institute, Puducherry, India

${ }^{2}$ Department of Obstetrics and Gynaecology, NMC, Puducherry, India
\end{abstract}

Received: 19 July 2019

Accepted: 29 July 2019

\author{
*Correspondence: \\ Dr. Swaramya C., \\ E-mail: swaramya@gmail.com
}

Copyright: () the author(s), publisher and licensee Medip Academy. This is an open-access article distributed under the terms of the Creative Commons Attribution Non-Commercial License, which permits unrestricted non-commercial use, distribution, and reproduction in any medium, provided the original work is properly cited.

\begin{abstract}
Background: The objective of this study was to analyse distribution of predisposing risk factors for ectopic pregnancy and to study the various modalities of management instituted along with surgical characteristics.

Methods: This is a retrospective data analysis of tubal ectopic pregnancies (EP) managed in a tertiary rural referral centre over three years.

Results: A total of 160 women were managed for tubal EP. Majority of the women belonged to the age group of 21 30 years (73\%). Multigravidae constituted $71.3 \%$ of the women and overall, $90.6 \%$ women conceived spontaneously. History of ovulation induction was present in $3.7 \%$ of women, IUI in $1.2 \%$ and IVF in $4.4 \%$. Risk factors encountered in the study include previous EP (9.4\%), history of tubal sterilisation $(6.9 \%)$, caesarean section (13.1\%), PID (7.5\%), miscarriage $(25 \%)$, tubal recanalization $(3.7 \%)$. Conservative management was instituted in $16.8 \%$. Amongst the women managed surgically, $67.5 \%$ underwent laparotomy with the remaining being managed laparoscopically. Of the surgically managed patients $72.9 \%$ had ruptured EP. There was a predominance of right sided ectopic in our study $(79 \%)$ and ampullary region of the fallopian tube was the most common site of tubal EP $(81.2 \%)$. The most common procedure performed was total salpingectomy (56.4\%). Supportive treatment with blood transfusion was required amongst $18.8 \%$ of the women who had EP. In the postoperative period, fever was noted in $13.5 \%$ of women and $2.5 \%$ needed intensive care unit admission for hemodynamic stabilisation. The incidence of wound discharge was $12 \%$ of women who underwent surgery.

Conclusions: This study underpins the importance of early diagnosis, appropriate clinical managementwith timely intervention to improve outcomes associated with EP and to prevent severe morbidity and mortality.
\end{abstract}

Keywords: Conservative management, Laparoscopy, Laparotomy, Risk factors, Ruptured ectopic, Surgical management, Tubal ectopic

\section{INTRODUCTION}

Ectopic pregnancy (EP) is a leading cause of morbidity albeit potential mortality in the first trimester. The incidence of EP amongst women seeking health care services during early pregnancy is $2-3 \%$. Although the incidence has remained relatively static over the last 15 years, associated mortality has decreased, though not significantly. ${ }^{1}$ Predisposition to EP is influenced by risk factors such as pelvic inflammatory disease, previous EP, adhesions due to prior pelvic surgeries or caesarean delivery, tubal sterilisation, prior tubal recanalization and history of miscarriage, previous infertility and assisted reproductive techniques. $^{2-5}$ There is a wide variation in 
the incidence of EP in various populations and risk largely varies with ethnicity. ${ }^{6}$ Depending on the clinical presentation, management options could be conservative or surgery. Conservative options include expectant management and various medical treatment protocols. The majority of tubal EP are managed surgically. Laparoscopic surgery when clinically relevant is preferable to laparotomy and is associated with lower morbidity, faster recovery and is cost effective in tubal EP. ${ }^{7,8}$ By convention, laparotomy is considered the best surgical approach for ruptured EP with hemodynamic instability. Management modality is widely influenced by available resources and clinical expertise and it is imperative to take into account local guidelines while formulating management protocols.

Authors embarked on this retrospective analysis with the following aims

- To study the demographic characteristics of women presenting with EP

- To analyse the distribution of predisposing risk factors for ectopic pregnancy

- To study the various modalities of management instituted along with surgical characteristics.

\section{METHODS}

This was a retrospective cohort study of women with tubal ectopic pregnancies presenting to the department of Obstetrics and Gynecology, MGMCRI, a rural based tertiary care teaching institute in Pondicherry. Patients who presented with a final diagnosis of EP over a 3 year period (April 2015-March 2018) were included in the study. Women with conditions mimicking EP who presented with acute abdomen with eventual alternative diagnoses were excluded. Patients were identified from admission registers and data was collected from their case records. A total of 160 cases of tubal ectopic pregnancies were analysed. Relevant information identified included demographic characteristics, clinical attributes, associated risk factors, management modalities, surgical characteristics and blood transfusion. The intra-operative details of surgical management were collected from operation theatre notes. The type of anesthesia, site of ectopic pregnancy, procedures performed and presence of hemoperitoneum noted. Post-operative morbidity including fever, wound discharge, wound dehiscence, secondary suturing and urinary tract infection were also noted.

\section{Statistical analysis}

Patients data was recorded in Microsoft excel spreadsheet and analysed using SPSS software version 19.0. Descriptive statistics were used to analyse the subject's baseline characteristics such as age, parity, period of gestation, site of ectopic. Percentages and frequencies were used for the description of categorical data. Mean and standard deviation were used for continuous data.

\section{RESULTS}

Over the study period of 3 years, 160 women were managed for tubal EP. Majority of the women belonged to the age group of 21-30 years (73\%), though more frequently noted amongst those aged between 26 and 30 years $(42.5 \%)$. Primigravidae constituted only $28.7 \%$ of the women, while $71.3 \%$ comprised multigravidae. Marital status was studied, and 3 women were unmarried. The educational status of majority of the women was up to secondary schooling $(68.7 \%)$. History of miscarriage was present in $25 \%$ of women. Mode of conception was spontaneous in $93.1 \%$ while the remaining women conceived following various assisted reproductive techniques. The mean gestational age of the study population is 48.1 days. The socio- demographic factors have been summarised in Table 1 .

Table 1: Socio-demographic factors of the study participants $(\mathrm{N}=160)$.

\begin{tabular}{|c|c|c|c|}
\hline $\begin{array}{l}\text { Sl. } \\
\text { No. }\end{array}$ & $\begin{array}{l}\text { Characteristics of ectopic } \\
\text { patients }\end{array}$ & Number & $\%$ \\
\hline \multirow[t]{7}{*}{1} & Age category in years & & \\
\hline & $<=20$ & 7 & 4.3 \\
\hline & $21-25$ & 49 & 30.6 \\
\hline & $26-30$ & 68 & 42.5 \\
\hline & $31-35$ & 29 & 18.1 \\
\hline & $36-40$ & 5 & 3.1 \\
\hline & $40-45$ & 2 & 1.25 \\
\hline \multirow[t]{3}{*}{2} & Gravida status & & \\
\hline & Primi & 46 & 28.75 \\
\hline & Multi & 114 & 71.25 \\
\hline \multirow[t]{3}{*}{3} & Marital status & & \\
\hline & Married & 157 & 98.12 \\
\hline & Unmarried & 3 & 1.8 \\
\hline \multirow[t]{4}{*}{4} & Level of education & & \\
\hline & Primary & 32 & 20 \\
\hline & Secondary & 110 & 68.7 \\
\hline & Tertiary & 18 & 11.2 \\
\hline \multirow[t]{5}{*}{5} & Previous miscarriage status & & \\
\hline & No. of miscarriage & 120 & 75 \\
\hline & 1 & 31 & 32.5 \\
\hline & 2 & 4 & 2.6 \\
\hline & 3 & 5 & 3.12 \\
\hline \multirow[t]{5}{*}{6} & Type of conception & & \\
\hline & Spontaneous & 145 & 90.6 \\
\hline & Ovulation induction & 6 & 3.75 \\
\hline & IUI & 2 & 1.2 \\
\hline & IVF & 7 & 4.4 \\
\hline
\end{tabular}

Risk factors encountered in the study include a history of EP (9.4\%), tubal sterilisation (6.9\%), LSCS (13.1\%), PID $(7.5 \%)$, miscarriage $(25 \%)$, tubal recanalization $(3.7 \%)$. Intraoperative findings of PID detected include tubercles on the surface of the tube, fimbrial adhesions, hydrosalpinx, uterosacral thickening or nodularity and altered anatomy of pouch of Douglas. 


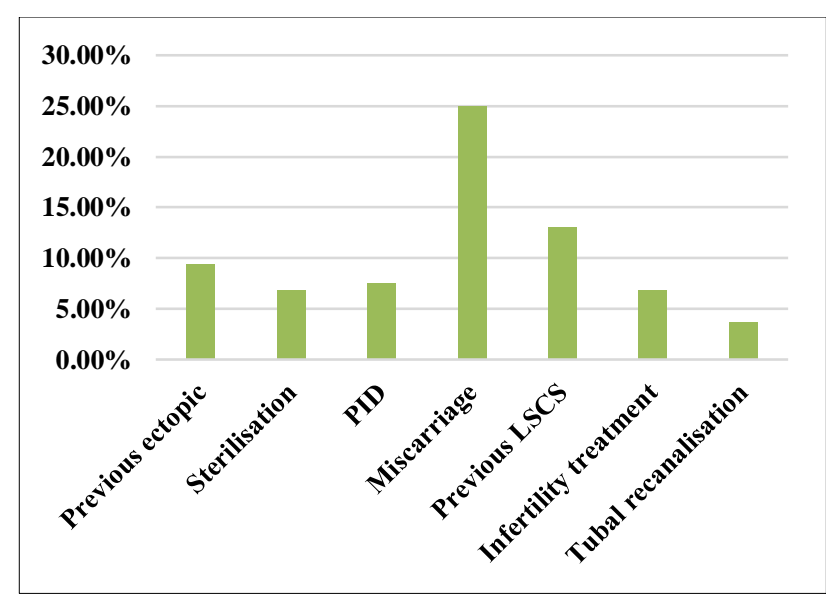

Figure 1: Distribution of risk factors for ectopic pregnancy.

\section{Treatment options}

An overwhelming majority of women presented with ruptured EP which was later confirmed by the presence of hemoperitoneum intraoperatively. Conservative management was instituted in $16.8 \%$ all of whom were hemodynamically stable and had tubal ectopic confirmed by transvaginal ultrasound with serum beta HCG less than $1500 \mathrm{IU}$. Expectant management was given to $2.5 \%$ while $14.3 \%$ received systemic methotrexate as medical management. One patient went on to have hemoperitoneum 24 hours after administration of systemic methotrexate which was managed surgically by laparotomy and total salpingectomy. A total of $83.2 \%$ women were managed surgically either due to hemodynamic instability or due to large size of ectopic mass $(>3.5 \mathrm{~cm})$ or serum beta HCG levels greater than 1500 IU. Amongst the women managed surgically, $67.5 \%$ underwent laparotomy with the remaining being managed laparoscopically. Supportive treatment with blood transfusion was required amongst $18.8 \%$ of the women who had EP. A pictorial representation of managements options is presented in Figure 2.

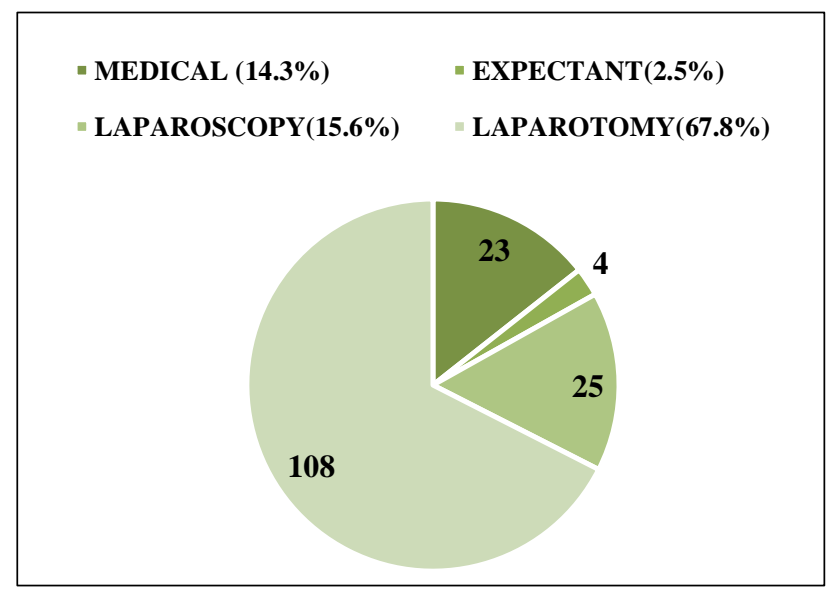

Figure 2: Treatment options instituted for the management of tubal ectopic pregnancy $(\mathrm{N}=160)$.
Table 2: Management details of the ectopic pregnancy ( $N=160)$.

\begin{tabular}{|lll|}
\hline $\begin{array}{l}\text { Type of management } \\
\text { Intervention }\end{array}$ & Frequency & Percentage \\
\hline Surgical & 133 & 83.2 \\
\hline Conservative & 27 & 16.8 \\
\hline Expectant & 4 & 2.5 \\
\hline Medical & 23 & 14.3 \\
\hline Route of surgery & 108 & 67.5 \\
\hline Laparotomy & 25 & 15.6 \\
\hline Laparoscopy & 30 & 18.8 \\
\hline $\begin{array}{l}\text { Blood transfusion } \\
\text { received (N=160) }\end{array}$ & & \\
\hline
\end{tabular}

Table 3: Surgical procedures performed for ruptured ectopic and patients who are not eligible for conservative management $(\mathrm{N}-133)$.

\begin{tabular}{|lll|}
\hline $\begin{array}{l}\text { Surgical procedure } \\
\text { performed }\end{array}$ & Frequency & Percentage \\
\hline Partial salpingectomy & 51 & 38.3 \\
\hline Total salpingectomy & 75 & 56.4 \\
\hline Wedge resection & 2 & 1.5 \\
\hline Peritoneal lavage & 5 & 3.75 \\
\hline Type of Anaesthesia & & \\
\hline Spinal & 107 & 80.4 \\
\hline General & 26 & 19.5 \\
\hline
\end{tabular}

The most common procedure performed was total salpingectomy $(56.4 \%)$.

Tubal abortion was noted in $3.7 \%$ women who underwent peritoneal lavage. Two women had interstitial EP and underwent wedge resection.

General anesthesia was employed for patients presenting with shock and hemodynamic instability whereas regional anesthesia in the form of spinal was the preferred choice for stable patients.

Of the surgically managed patients, $72.9 \%$ had ruptured ectopic as confirmed intra-operatively.

There was a predominance of right sided ectopic in our study $(79 \%)$ and ampullary region of the fallopian tube was the most common site of tubal EP $(81.2 \%)$.

Patients data pertaining to postoperative morbidity was analysed. The incidence of wound discharge was $12 \%$ of women who underwent surgery. Wound dehiscence was noted in $3.7 \%$ of the women and secondary suturing was needed for $3 \%$.

Although two patients required ICU admission for hemodynamic stabilisation, there was no maternal mortality. 
Table 4: Intra-op findings of patients with tubal ectopic pregnancy managed surgically $(\mathrm{N}=133)$.

\begin{tabular}{|l|lll|}
\hline $\begin{array}{l}\text { S1. } \\
\text { No. }\end{array}$ & $\begin{array}{l}\text { Characteristics of } \\
\text { ectopic patients }\end{array}$ & Frequency & $\%$ \\
\hline 1 & Side & & \\
\hline & Right & 79 & 59.39 \\
\hline & Left & 54 & 40.6 \\
\hline 2 & Unruptured & 31 & 23.3 \\
\hline & Ruptured & 97 & 72.9 \\
\hline & Tubal abortion & 5 & 3.75 \\
\hline 3 & Site in the tube & & \\
\hline & Ampullary & 108 & 81.2 \\
\hline & Isthmic & 19 & 14.2 \\
\hline & Interstitial/angular & 2 & 1.5 \\
\hline & Fimbrial & 4 & 3 \\
\hline 4 & $\begin{array}{l}\text { Haemoperitoneum } \\
\text { present }\end{array}$ & 97 & 72.9 \\
\hline
\end{tabular}

Table 5: Post-operative morbidity of surgically managed patients $(n=133)$.

\begin{tabular}{|lll|}
\hline Postoperative morbidity & Frequency & Percentage \\
\hline Fever & 18 & 13.5 \\
\hline Wound discharge & 16 & 12 \\
\hline Wound dehiscence & 5 & 3.7 \\
\hline Secondary suturing & 4 & 3 \\
\hline Urinary tract infection & 7 & 5.3 \\
\hline $\begin{array}{l}\text { Intensive care unit } \\
\text { admission }\end{array}$ & 2 & 1.5 \\
\hline
\end{tabular}

\section{DISCUSSION}

Ectopic pregnancy is the implantation of the blastocyst outside the normal uterine cavity. The various ectopic locations include fallopian tubes, ovaries, cervix, abdominal cavity or caesarean scar. Fallopian tube is the most common location of EP.

In India, cases of EP often go unreported and there is a lack of robust data on the incidence of EP.The incidence of EP in various studies in developed countries ranges between 6.4 and 16.2/1000 pregnancies Few Indian studies have estimated the incidence of EP at 5.6 to $10 / 1000$ deliveries. ${ }^{3,9-11}$ In this study, the incidence of EP is $22 / 1000$ deliveries. The relatively high incidence of EP in our setup could be partly explained by the reason that the hospital is a key referral tertiary institute located in an otherwise low-resource rural area.

EP can present with myriad symptoms, right from the oft described triad of amenorrhoea, acute lower abdominal pain, vaginal bleeding to symptoms such as giddiness, syncope and vague complaints of diarrhea or pelvic discomfort. $^{3,12}$ Commonly employed diagnostic modalities for acute presentation of EP include a preliminary urine pregnancy test which is then aided by imaging by transvaginal ultrasound. In the event of an inconclusive imaging result, clinical findings with presence of hemoperitoneum may guide the diagnosis. ${ }^{7,13}$ In our study, urine pregnancy test was performed in all women at the time of presentation and all 160 women tested positive. Four women had inconclusive sonographic findings, of whom one woman was eventually administered systemic methotrexate (diagnosed based on serial beta hCG values), while the other 3 women underwent diagnostic laparoscopy and were found to have unruptured tubal EP.

Risk of EP is increased with the conventionally associated factors which include previous EP previous adnexal, pelvic and abdominal surgery, previous infertility, previous miscarriage, chlamydial infection (Adjusted odds ratio varying between 1.64-3.18). History of sterilisation also increases the risk of EP. ${ }^{14}$ In the present analysis, history of prior miscarriage was the most common risk factor for EP (25\%), followed by previous cesarean section, previous EP, presence of PID, preceding infertility, previous sterilisation and tubal recanalisation. Invitro fertilisation is associated with significantly higher rate of EP $(1.4 \%)$ when compared with Intrauterine insemination (1.1\%). Infertility attributed to tubal factor and multiple embryo transfer are strongly associated with increased incidence of EP. ${ }^{15}$ In the present study, $90.6 \%$ women conceived spontaneously. History of ovulation induction was present in $3.7 \%$ of women, IUI in $1.2 \%$ and IVF in $4.4 \%$.

Notwithstanding the plethora of diagnostic modalities for accurate diagnosis of EP, formulating an optimal plan of management could pose a dilemma in women who are hemodynamically stable with minimal symptoms. The success rate of expectant management in appropriately selected women reaches $50 \% .^{16}$ Overall, we managed $2.5 \%$ of women expectantly. Systemic methotrexate is widely used for medical management of EP. Methotrexate is an inhibitor of the enzyme dihydrofolate reductase (DHFR) and hence interferes with the synthesis of DNA and RNA. With proper patient selection, the success of systemic therapy reaches rates comparable to conservative surgery. ${ }^{17}$ In this study, $14.3 \%$ of women were managed with systemic methotrexate according to institute protocol.

The route of surgery is often decided based on available resources, expertise and clinical presentation. Laparoscopy serves as a diagnostic as well as a therapeutic option in the same sitting. Laparoscopic approach is associated with shorter hospital admission and faster recovery. Reproductive outcomes of recurrent $\mathrm{EP}$ and subsequent successful intrauterine pregnancy were comparable between open and laparoscopic approach. ${ }^{18}$ We managed $15.6 \%$ women by laparoscopy, while majority underwent laparotomy (67.5\%). Common post-operative complications include wound infection, ICU admission, urinary tract infection and complications due to blood transfusion. The rate of wound dehiscence was $3.7 \%$ in this study which was comparable to similar 
studies (4.7-5.6\%). On the contrary, rates of ICU admission was low in this study $(1.5 \%)$. $^{3-11}$

\section{CONCLUSION}

More robust trials are required to evaluate the role of expectant management, the ideal dose and route of pharmacotherapy with standardised protocols, the timing and route of surgery and the role of conservative surgeries with due consideration for future fertility. The availability of expertise and equipment for laparoscopic surgery and case selection is important for providing best possible care to these patients when presenting acutely. Early diagnosis and treatment of ectopic pregnancy is the only modality available to prevent tubal rupture and its associated morbidity.

\section{Funding: No funding sources}

Conflict of interest: None declared

Ethical approval: The study was approved by the Institutional Ethics Committee

\section{REFERENCES}

1. Cantwell R, Clutton-Brock T, Cooper G, Dawson A, Drife J, Garrod D, et al. Saving Mothers' Lives: Reviewing maternal deaths to make motherhood safer: 2006-2008. The Eighth Report of the Confidential Enquiries into Maternal Deaths in the United Kingdom. BJOG Int J Obst Gynaecol. 2011;118:1-203.

2. Falcone T, Mascha EJ, Goldberg JM, Falconi LL, Mohla G, Attaran M. A study of risk factors for ruptured tubal ectopic pregnancy. J Women's Heal. 1998;7(4):459-63.

3. Pranathi P, Madhavi Y. A clinical analysis of ectopic pregnancies in a tertiary care hospital in Hyderabad. Asian Pac J Heal Sci. 2018;5(1):14-24.

4. Sindos M, Togia A, Sergentanis TN, Kabagiannis A, Malamas F, Farfaras A, et al. Ruptured ectopic pregnancy: risk factors for a life-threatening condition. Arch Gynecol Obstet. 2009;279(5):621.

5. Ankum WM, Mol BW, Van der Veen F, Bossuyt PM. Risk factors for ectopic pregnancy: a metaanalysis. Fertil Steril. 1996;65(6):1093-9.

6. Zwart JJ, Jonkers MD, Richters A, Öry F, Bloemenkamp KW, Duvekot JJ, et al. Ethnic disparity in severe acute maternal morbidity: a nationwide cohort study in the Netherlands. Euro J Pub Heal. 2010;21(2):229-34.

7. Elson CJ, Salim R, Potdar N, Chetty M, Ross JA, Kirk EJ. Diagnosis and management of ectopic pregnancy. BJOG. 2016;.123:e15-e55.
8. Mol F, Mol BW, Ankum WM, Van der Veen F, Hajenius PJ. Current evidence on surgery, systemic methotrexate and expectant management in the treatment of tubal ectopic pregnancy: a systematic review and meta-analysis. Human Reproduction Update. 2008;14(4):309-19.

9. Kumar V, Gupta J. Tubal ectopic pregnancy. BMJ Clin Evid. 2015 Nov 16;2015:1406.

10. Shetty S. A clinical study of ectopic pregnancies in atertiary care hospital of Mangalore, India. Innov J Med Health Sci. 2014;4(1).

11. Tahmina S, Daniel M, Solomon P. Clinical analysis of ectopic pregnancies in a tertiary care centre in Southern India: a six-year retrospective study. J Clin Diagn Res: JCDR. 2016;10(10):QC13.

12. Ranji GG, Usha Rani G, Varshini S. Ectopic Pregnancy: Risk Factors, Clinical Presentation and Management. J Obstet Gynaecol Ind. 2018;68(6):487-92.

13. Panelli DM, Phillips CH, Brady PC. Incidence, diagnosis and management of tubal and nontubal ectopic pregnancies: a review. Fertil Res Prac. 2015;1(1):15.

14. Li C, Zhao W-H, Zhu Q, Cao S-J, Ping H, Xi X, et al. Risk factors for ectopic pregnancy: a multi-center case-control study. BMC Pregnancy Childbirth. 2015:15.

15. Santos-Ribeiro S, Tournaye H, Polyzos NP. Trends in ectopic pregnancy rates following assisted reproductive technologies in the UK: a 12-year nationwide analysis including 160000 pregnancies. Human Reprod. 2016;31(2):393-402.

16. Rodrigues SP, de Burlet KJ, Hiemstra E, Twijnstra $\mathrm{AR}$, van Zwet EW, Trimbos-Kemper $\mathrm{TC}$, et al. Ectopic pregnancy: when is expectant management safe?. Gynecol Surg. 2012;9(4):421-6.

17. Practice Committee of the American Society for Reproductive Medicine. Medical treatment of ectopic pregnancy: a committee opinion. Fertil steril. 2013;100(3):638-44.

18. Duggal BS, Tarneja P, Sharma RK, Rath SK, Wadhwa RD. Laparoscopic management of ectopic pregnancies. Med J Arm Forces Ind. 2004;60(3):2203 .

Cite this article as: Galidevara $C$, Swaramya $C$ An analysis of tubal ectopic pregnancy in a rural tertiary care hospital in India: a retrospective study. Int J Reprod Contracept Obstet Gynecol 2019;8:3466-70. 